Reusable endoscopic water bottles: is daily renewal really necessary? Peer-reviewed author version

Jouck, D.; MAGERMAN, Koen; BRUCKERS, Liesbeth; WAUMANS, Luc; Forier, Annemie; Blommen, M. \& Walgraeve, D. (2018) Reusable endoscopic water bottles: is daily renewal really necessary? In: JOURNAL OF HOSPITAL INFECTION, 100(3), p. E135-E137.

DOI: 10.1016/j.jhin.2018.07.025

Handle: http://hdl.handle.net/1942/27906 


\section{Reusable endoscopic water bottles - is daily renewal really necessary?}

Jouck $D^{a}$, Magerman $K^{a, b}$, Bruckers $L^{c}$, Waumans $L^{a, b}$, Forier $A^{a}$, Blommen $M^{a}$, Walgraeve $D^{d}$

aDepartment of Infection Prevention and Control, Jessa Hospital, Hasselt, Belgium

${ }^{b}$ Clinical Laboratory, Jessa Hospital, Hasselt, Belgium

'Interuniversity Institute for Biostatistics and Statistical Bioinformatics, Hasselt University, Hasselt, Belgium

${ }^{\mathrm{d} D e p a r t m e n t}$ of Gastroenterology, Jessa Hospital, Hasselt, Belgium 


\section{Summary}

Most guidelines recommend replacing endoscopic water bottles at least daily with newly sterilized or high-level disinfected water bottles. All these recommendations, however, are mainly based on expert opinions and outbreak reports. We tested the water quality from water bottles used in a gastrointestinal endoscopy unit where water bottles were used up to five days. The results show that the reuse of water bottles for more than one day is inadequate. The expert opinion of changing water bottles daily rather than after five days, is a sensible and safer option. 


\section{Introduction}

Nowadays, flexible endoscopes are indispensable in the medical field and are routinely used for a variety of diagnostic, therapeutic and surgical purposes. Many devices are often used along with these flexible endoscopes, including water bottles. These water bottles consist of a water container and a lid with a fixed (black) connection hose (further on just described as 'water bottle'). They are used for insufflation of air and for cleaning the distal lens of the endoscope during the procedure.

There is relatively little known about the exact role of contaminated water bottles in the transmission of micro-organisms and causing infections. The majority of these studies are published more than 20 years ago, before strict cleaning and disinfection requirements that are currently applied, existed. A few studies suggest that the improper use of reusable water bottles may be a source of spread of micro-organisms, the cause of infections or outbreaks [1-5].

To prevent the spread of microorganisms, many guidelines describe meticulously which cleaning and disinfection steps these endoscopes have to go through after use $[3,6-10]$. In these guidelines, it is often advised to fill the water bottles with sterile water and to change this sterile water daily $[3,4,6,8,9]$ or after each endoscopy session [7]. As well as the sterile water, the water bottle must be replaced by a new sterilized or high-level disinfected water bottle at least daily [2-4,6-8]. Some guidelines even recommend changing the water bottle after each endoscopy session $[9,10]$ or before each endoscopic retrograde cholangiopancreatography procedure [3].

All these recommendations, however, are compiled mainly based on expert opinion and outbreak reports. Until now, little to no data pertaining to the safety or potential risk exist for the optimal replacement intervals for these water bottles. 


\section{Methods}

The study was conducted from June 10, 2016, until July 10, 2017, at a 981-bed tertiary hospital in Belgium. Water bottles from one of the two gastrointestinal endoscopy units were tested. This endoscopy unit used reusable water bottles from Olympus (model MAJ-901) and Pentax (model OSH4) which were autoclaved weekly. The water bottles were emptied before the first endoscopic examination of the day and then immediately, without drying or disinfection, refilled with a new quantity of sterile water.

In addition to the replacement frequency of the water bottles, current national and international reprocessing guidelines of flexible scopes and devices such as backflow-prevention-valves were carefully applied after each endoscopy session [6-8]. Immediate pre-cleaning at the point of use, followed by manual cleaning and high-level disinfection in automated endoscope reprocessors was performed at all times. The endoscopes were stored in a drying cabinet.

The sterilization of the water bottles was carried out through autoclaving in accordance with the manufacturer's recommendations. The design of re-useable endoscope water bottles made it difficult to reprocess as well as disinfect or sterilize [5]. These challenges are manifested by the presence of an O-ring, a lid with a fixed water inlet hose and a fixed black connecting tube containing a narrow internal channel, amongst a number of other aspects. In order to validate the sterilization process, three newly unpacked autoclaved water bottles were filled with sterile water. Afterwards, a water sample was taken as described in the methods below. The absence of microbial growth in the three samples showed adequate contamination control.

\section{Sampling method}

179 samples were taken after the last endoscopy of the day from Monday to Friday (duration in days 1-5). During the weekend there were no samples taken since there was no endoscopic activity. Before each sampling, hands were washed with soap and water and disinfected with an alcoholbased hand sanitizer. To prevent contamination from the environment, the metal tip of the black connection tube was disinfected with ethanol $70 \%$ and allowed to dry by evaporation before the sample was taken. For each sample, approximately $50 \mathrm{ml}$ of the water in the water bottle was collected in an aseptic way through the black connection tube into a clearly labelled sterile plastic specimen container.

The aim of this sampling method was to imitate the practical working conditions as much as possible. The samples were collected merely through the force of gravity by holding the water bottle upside down, so the water bottle was not opened. No additional tools like syringes or sterile brushes, were utilized. The consequence of this method was that the water from the water bottles was only sampled through the air supply channel of the black connection tube, and not through the water supply channel.

After collection, the samples were placed in a cooler bag and immediately transported to the laboratory for analysis. All samples arrived at the laboratory within one hour after collection. To prevent a positive sample from a water bottle for example on day four being re-sampled on day five, 
the same water bottle was never sampled more than once, until it was re-sterilized. This was closely monitored through a unique coding, applied to each individual water bottle.

\section{Microbiologic analysis}

Each individual sample was filtered through a membrane filter with a pore size of $0.45 \mu \mathrm{m}$. Thereafter, the filter was put aseptically with sterile forceps onto a R2A agar plate. To allow optimal growth of aerobic mesophilic micro-organisms, plates were incubated at $30 \pm-2^{\circ} \mathrm{C}$ under atmospheric conditions for five days. After incubation, the total number of colony forming units (cfu) was counted. For each type of growth, an identification was carried out using matrix-assisted laser desorption ionization time-of-flight mass spectrometry (MALDI-TOF). Cultures for mycobacteria or legionella species were not performed on any samples. 


\section{Results and Discussion}

There is little, to no knowledge on the level of contamination of water samples collected from water bottles, that poses a significant risk to the patient. There are no generally accepted international criteria. Based on the criteria for the last endoscopic rinse water of the EN ISO 15883 in the British and Dutch guidelines $[8,10]$, the classification as described in the first column of table I was utilized.

A total of 179 samples were tested between June 10,2016, and July 10, 2017. Overall $25.14 \%$ or 45 samples contained more than $9 \mathrm{cfu} / \mathrm{ml}$, of which 39 came from water bottles that had been used for more than one day. Table I shows the results of water samples from water bottles that were used for one day compared to water bottles used for several days. The difference between the duration of use of one day versus more than one day is statistically significant for samples with more than 100 $c f u / 100 \mathrm{ml}(p=0.0091$, Fisher Exact test). The overall difference (across all classifications) between one day versus more than one day was very close to being statistical significant $(p=0.0514$, Fisher Exact test).

Bacterial growth from the water samples included mainly skin flora and water saprophytes such as Stenotrophomonas maltophilia and Sphingomonas species. Pseudomonas aeruginosa was detected in 11 of the 179 samples, all of which were in water bottles that had been used for more than one day. This amounts to $7.6 \%$ of all samples for this period of usage. The presence or absence of Pseudomonas aeruginosa in water bottles that were used for 1 day or several days is not statistically significant $(p=0.1276$, Fisher Exact test).

Despite the fact that the water bottles were always filled with sterile water, microbial growth occurred. Causes of contamination could be due to malfunctioning backflow prevention valves, improper use of hand disinfection before filling the water bottles or contamination during connection or disconnection of the black connection tubes.

The results show that the reuse of water bottles for more than one day is inadequate. However, the clinical impact is difficult to evaluate and is probably limited. No major infections were notified. After use, each endoscope undergoes several thorough cleaning and disinfection steps to prevent the transmission of micro-organisms. Hence it would be contradictory to use less stringent measures for these water bottles and to tolerate a high number of micro-organisms with a potential risk for patient safety.

The expert opinion of changing water bottles daily rather than after five days, is a sensible and safer option. Furthermore, we need to consider whether stricter guidelines may be right to recommend replacing water bottles after each endoscopy session, because we detected more than $9 \mathrm{cfu} / 100 \mathrm{ml}$ in $17 \%$ of samples after only one day of water bottle utilization. However, this needs to be further investigated.

\section{CONFLICTS OF INTEREST}

None declared.

\section{FUNDING SOURCE}


This research did not receive any specific grant from funding agencies in the public, commercial, or not-for-profit sectors.

\section{REFERENCES}

1. Kovaleva J, Peters FT, van der Mei HC, Degener JE. Transmission of infection by flexible gastrointestinal endoscopy and bronchoscopy. Clin Microbiol Rev. 2013 Apr;26(2):231-54. doi: 10.1128/CMR.00085-12.

2. Food and Drug Administration (FDA). (2016, November). Mitigating the Risk of CrossContamination From Valves and Accessories Used for Irrigation Through Flexible Gastrointestinal Endoscopes; Guidance for Industry and Food and Drug Administration Staff; Available at:

https://www.fda.gov/downloads/MedicalDevices/DeviceRegulationandGuidance/GuidanceD ocuments/UCM430550.pdf

3. Public Health Agency of Canada. (2010). Infection Prevention and Control Guideline for Flexible Gastrointestinal Endoscopy and Flexible Bronchoscopy. Available at: https://www.canada.ca/content/dam/phac-aspc/migration/phac-aspc/noissinp/guide/endo/pdf/endo-eng.pdf

4. Society of Gastroenterology Nurses and Associates, Inc. (2014, September). SGNA position statement: Water and irrigation bottles used during endoscopy. Available at: https://www.sgna.org/Portals/0/Education/PDF/PositionStatements/WaterandlrrigationBottles final.pdf

5. Pearce P. (2005). Laboratory evaluation of Endoscope Water Bottles. Report prepared on behalf of Medivators Inc. by Nova Biologicals, Inc. Available at: http://www.medivators.com/sites/default/files/minntech/documents/Laboratory\%20Bottle \%20Study Sept\%202017 50098-1505\%20Rev\%20A.pdf

6. Reprocessing Guideline Task Force, Petersen BT, Cohen J, Hambrick RD 3rd, Buttar N, Greenwald DA, et al. Multisociety guideline on reprocessing flexible Gl endoscopes: 2016 update. Gastrointest Endosc. 2017 Feb;85(2):282-294.e1. doi: 10.1016/j.gie.2016.10.002.

7. Beilenhoff $U$, Neumann CS, Rey JF, Biering H, Blum R, Cimbro M, et al. ESGE-ESGENA Guideline: cleaning and disinfection in gastrointestinal endoscopy. Endoscopy. 2008 Nov;40(11):939-57. doi: 10.1055/s-2008-1077722.

8. The steering group for flexible endoscope cleaning and disinfection (SFERD). (2017, September). Professional handbook Flexible Endoscopes Cleaning and Disinfection. Version 4.1. Available at: https://www.infectiepreventieopleidingen.nl/downloads/SFERDHandbook4 1.pdf

9. Gastroenterological Society of Australia (GESA), Australian Gastrointestinal Endoscopy Association (AGEA) and Gastroenterological Nurses College of Australia. (2010, ${ }^{\text {th }}$ edition). Infection control in Endoscopy. Available at: http://cart.gesa.org.au/membes/files/Clinical\%20Guidelines\%20and\%20Updates/Infection C ontrol in Endoscopy Guidelines 2014.pdf

10. British Society of Gastroenterology Endoscopy Committee. (2016, November). Guidance for Decontamination of Equipment for Gastrointestinal Endoscopy: 2017 Edition. Available at: https://www.bsg.org.uk/resource/guidance-on-decontamination-of-equipment-forgastrointestinal-endoscopy-2017-edition.html 


\section{Table I}

The classification of results for water bottles used for one day compared to water bottles used for several days.

\begin{tabular}{|c|c|c|c|c|}
\hline \multirow{3}{*}{ Classification } & \multicolumn{4}{|c|}{ Duration of use } \\
\hline & \multicolumn{2}{|c|}{1 day } & \multicolumn{2}{|c|}{ 2-5 days } \\
\hline & Number & Percentage (\%) & Number & Percentage (\%) \\
\hline \\
\hline acceptable & 19 & 55.88 & 70 & 48.28 \\
\hline $1-9 \mathrm{cfu} / 100 \mathrm{ml}$ & & & & \\
\hline acceptable & 9 & 26.47 & 36 & 24.83 \\
\hline $\begin{array}{c}\text { 10-100 cfu / 100ml } \\
\text { questionable }\end{array}$ & 6 & 17.65 & 17 & 11.72 \\
\hline $\begin{array}{c}\text { > } 100 \text { cfu / 100ml } \\
\text { unacceptable }\end{array}$ & 0 & 0.00 & 22 & 15.17 \\
\hline
\end{tabular}

